\title{
Estimation of Seismic Site Response in the Tangshan Area, China, Using Deep Underground Records
}

\author{
by Koji Matsunami, Wenbo Zhang*, Kojiro Irikura, and Li-li Xie
}

\begin{abstract}
Site amplification in the Tangshan area, China, was analyzed using records of small events $\left(M_{\mathrm{L}} 2.9-4.4\right)$ observed by a strong motion array with a deep ( $-822 \mathrm{~m}$ ) underground station deployed between 1982 and 1984 following the 1976 Tangshan earthquake. The effect of destructive interference at the underground site due to surface reflections was confirmed to be negligible in this case. The source, propagation path, and site effects were separated simultaneously by linear inversion using the underground reference site. The $S$-wave quality factor was found to be approximated by the relation $29 f^{0.9}$ in the frequency range $1-10 \mathrm{~Hz}$. The conventional surface rock reference site was found to have a characteristic frequencydependent site effect, which increased markedly from the theoretical amplification factor of 2 over the frequency range of interest. A reference-independent technique assuming an $\omega$-squared source model was also introduced and produced results that were in good agreement with the results obtained using the underground reference. The reference-independent technique revealed the underground station to have a nearly flat response consistent with the theoretical response, indicating that an underground or borehole bedrock site is a better reference than a surface rock for seismic hazard analysis. The reference-independent technique produced accurate absolute site amplification factors for the area examined in this study, demonstrating the usefulness of the method for site effect analysis.
\end{abstract}

\section{Introduction}

The assessment of local site effects on seismic ground motions is of great significance in earthquake engineering research and applications. Several destructive earthquakes, such as the Loma Prieta earthquake in California in October 1989, the Northridge earthquake in California in January 1994, the Kobe earthquake in Japan in January 1995, and the western Tottori earthquake in Japan in October 2000, have demonstrated that the amplification of ground motion and associated damage to structures due to local site conditions is a very important consideration in seismic hazard analysis. The role of surface geology in seismic motions is important for both mitigating seismic hazard and detailed analyses of earthquake source characteristics. In fact, the accurate estimation of earthquake source parameters cannot be achieved without proper understanding of the local site and path effects. However, the characterization of ground motions with regard to local site conditions is a difficult task because of the complexity of surface geology and irregular topography. Several methods of analyzing site amplification have addressed these difficulties (Borcheredt, 1970; An-

*Present address: Disaster Prevention Research Institute, Kyoto University, Gokasho, Uji, Kyoto, 611-0011, Japan. drews, 1982; Iwata and Irikura, 1986; Phillips and Aki, 1986; Field and Jacob, 1995). A common aspect of these methods is the use of a nearby bedrock site as a reference. The critical assumption in these methods is that the record of a surface reference rock site is equivalent to the input motion at the base of the soil layer. However, a number of studies have revealed significant variability in surface ground motions over even small distances at both soil and rock sites (Cranswick, 1988; Menke et al., 1990; Vernon et al., 1991; Schneider et al., 1992; Steidl, 1993). This variability, particularly at rock sites, suggests that this basic assumption of equivalent motion may not hold above a sitedependent frequency (Steidl et al., 1996). Furthermore, from comparisons of ground motions recorded simultaneously at the surface and in boreholes, Steidl et al. (1996) showed that surface rock sites can exhibit anomalous site responses, which can lead to an underestimation of the seismic hazard if such sites are used as reference sites. This indicates that if the effect of the downgoing wave field (reflections from the surface) and the resulting destructive interference are carefully considered, the borehole bedrock ground motion can be regarded as a good reference motion for seismic hazard analysis (Boore and Joyner, 1997). However, as it is not 
economically feasible to drill a series of deep boreholes for estimating site amplification, a reference-independent technique is desirable.

Recently, Moya et al. (2000) and Jin et al. (2000) introduced the principle of genetic algorithms (GA) as an alternative method for inverting source spectra of earthquakes and site effects at stations. The inversion assumes Brune's (1970, 1971) source model for each event. Each source model is then used to compute the site effect at the station that has recorded the event. Assuming that the site effect at the station should be the same regardless of the event, GAs minimize the standard deviation of the site effect by searching for new source models. The inversion guarantees that the low-frequency flat levels and corner frequencies obtained at the end of the inversion are those that would correspond to the most stable site effect estimation. Thus, GA method is a source-dependent but reference-independent approach to estimating site effects.

If the source model reflects the real source mechanism, the site effect estimated by the GA method can be expected to represent the true absolute site amplification. However, when evaluating the site effect with assumed source spectra, the result of the reference-independent technique may be implicitly affected by a trade-off between the site and source effects. Therefore, this GA technique should be examined in more detail by comparing the results of GA analysis with measurements obtained using an underground or borehole rock site as a reference.

The main objective of the present study is to examine whether borehole rock sites are better references than surface rock sites for site response studies and whether a referenceindependent technique is effective for evaluating accurate absolute site amplifications. These analyses are performed using aftershock records of the 1976 Tangshan earthquake, recorded by a strong motion array with a deep $(-822 \mathrm{~m})$ underground rock site station in the Tangshan area. The effect of waves reflected from the surface to the underground site is examined, and the source, propagation path, and local site effects are separated simultaneously by linear inversion using an underground rock reference site. The same calculations are then performed using a surface rock reference site, and the results are compared. Finally, the site effects are estimated by a reference-independent technique similar to that of Moya et al. (2000), and the results are compared.

\section{Data}

\section{The Tangshan Earthquake Sequence}

A destructive earthquake of $M_{\mathrm{s}} 7.8$ struck the city of Tangshan, China, $160 \mathrm{~km}$ east of Beijing, on 28 July 1976 (Fig. 1; modified from Huang and Yeh, 1997). The focal depth of the Tangshan earthquake was $10 \mathrm{~km}$. A prominent surface rupture crossed the city, almost completely destroying it and heavily damaging the surrounding areas. On the same day, approximately $15 \mathrm{hr}$ later, the largest aftershock of $M_{\mathrm{s}} 7.1$ (the Luanxian earthquake) occurred about $45 \mathrm{~km}$ northeast of the mainshock. Another large aftershock of $M_{\mathrm{s}}$ 6.9 (the Ningho earthquake) occurred on 15 November 1976 to the southwest of Tangshan, near Ningho. The two aftershocks caused additional damage in the area. Over 800 aftershocks of $M_{\mathrm{L}} \geq 4$ were detected following the Tangshan earthquake from July 1976 to December 1976 (State Seismological Bureau, 1980). The aftershocks of the Tangshan earthquake were relocated by Schedlock et al. (1987). Figure 1a shows the epicenters of those aftershocks and the tectonic faults near the Tangshan area. The fault-plane solutions of the mainshock and the two large aftershocks determined by Huang and Yeh (1997) are also presented. The epicenter of the mainshock was located near the center of the Tangshan fault, and the two large aftershocks occurred at each end. Those two aftershocks were distributed in a long but somewhat narrow belt striking northeast, approximately $150 \times$ $30 \mathrm{~km}^{2}$ in extent. Most of the aftershocks were confined to the area between the Jiyunhe fault and the Luanxian-Loting fault. The aftershocks ranged in depth from shallow to about 20 km (Fig. 1b).

According to Huang and Yeh (1997), most of the crustal deformation of the Tangshan area was associated with a right-lateral strike slip on a north-northeast-striking fault rupture of the mainshock, together with the ruptures of the two large aftershocks. As shown in Figure 1a, the fault associated with the mainshock rupture can be divided into southern and northern subfaults with different strikes, dips, and rakes. In addition, the two large aftershocks are associated with normal faulting (the Luanxian earthquake) and left-lateral strike-slip faulting with a small normal component (the Ningho earthquake). Huang and Yeh (1997) reconstructed the rupture processes of the mainshock using the results of teleseismic waveform modeling by Nabelek et al. (1987) and coseismic surface deformation modeling. Huang and Yeh (1997) indicated that the rupture initiated from the northern boundary of the southern subfault (near the connective bend region around Tangshan) and propagated to the south. The rupture on the northern subfault was triggered 5.9 sec later at the southern end, propagating to the north. Thus, the mainshock was associated with two unilateral ruptures at each end. However, the rupture processes were considered bilateral at teleseismic distances (Butler et al., 1979; Nabelek et al., 1987; Xie and Yao, 1991).

\section{Observation Stations and Data}

An experimental strong motion array was deployed in the Tangshan area from 1982 to 1984, after the Tangshan earthquake, by a joint Chinese-American team Institute of Engineering Mechanics/California Institute of TechnologyU.S. Geological Survey-University of Southern California (IEM/CALTECH-USGS-USC). The digital accelerographs of the array were Kinemetrics PDR-1 instruments with FBA13 force-balance accelerometers. A total of 218 accelerograms were published by the team (China-U.S. Joint Project on Strong Ground Motion Measurements, 1989), encompassing 52 events of $M_{\mathrm{L}} 2.3-5.7$ from July 1982 to December 1984. Several stations of the array were located in an 
(a)

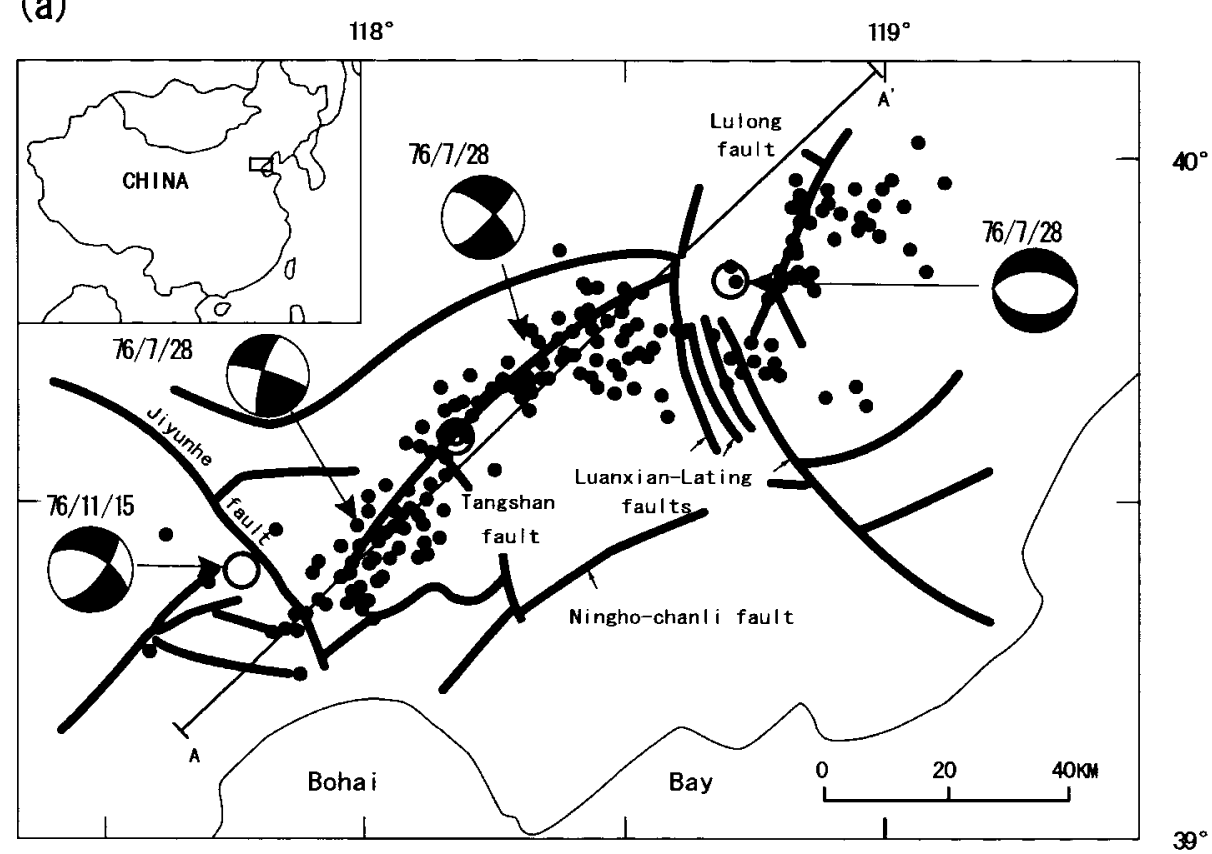

(b)

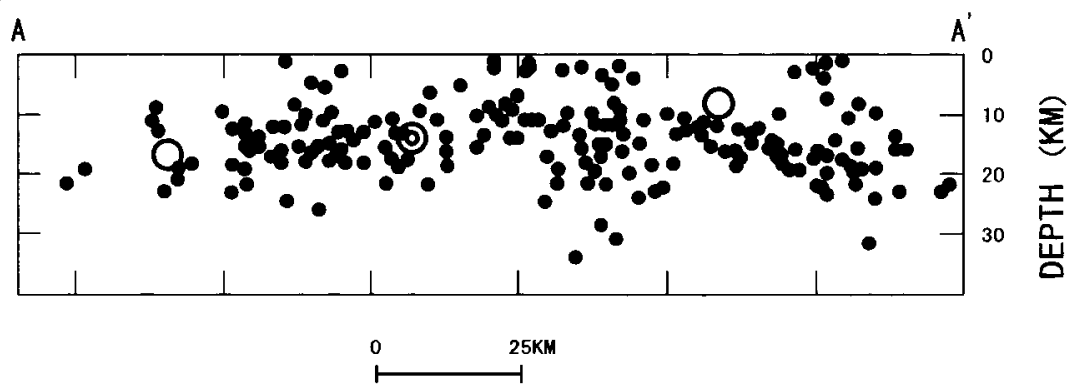

Figure 1. (a) Distribution of aftershocks (solid circles) of $M_{\mathrm{L}} \geq 4$ following the Tangshan earthquake from 28 July to 30 December 1976 (modified from Shedlock et al. [1987]). The major tectonic faults and lower hemisphere projections of the faultplane solutions of the mainshock (double open circle) and the two large aftershocks (large open circles) determined by Huang and Yeh (1997) are shown. (b) Hypocenter projections (solid circles) of aftershocks and major events (large open circles) on a vertical plane along $\mathrm{AA}^{\prime}$ in (a). This figure was modified from Huang and Yeh (1997).

underground tunnel of an abandoned coal mine. The deepest station was about $822 \mathrm{~m}$ below the surface.

In this study, 13 events recorded by nine stations were selected for analysis of site amplification in the Tangshan area. Figure 2 shows the distribution of events and station locations. As shown in this figure, the events and stations are located between the northern end of the Tangshan fault and the Luanxian-Loting fault. Station TS15 is an underground rock site station $(-822 \mathrm{~m})$, and station TS01 is a surface rock site station; they are used as references in this analysis. Table 1 lists the stations, locations, and site conditions, and Table 2 gives some parameters of the observed earthquakes and the recording stations. The magnitudes of these events were in the range 2.9-4.4, and the focal depths ranged from 4 to $10 \mathrm{~km}$.

\section{Methods}

The distance calculated from the $S$ - $P$ time was used as the hypocentral distance rather than the distance calculated using catalog coordinates because of the likely errors in the catalog. Bonilla et al. (1997) also used this technique. A 5sec time window was used to extract $S$ waves, and a $5 \%$ Hanning taper was applied to the time window. A 1.5- or 2sec time window before the $P$-wave arrival was used to examine the noise level, and only data with a signal-to-noise ratio of greater than 2 were used in the analysis. In this study, we analyzed only the horizontal component. The amplitude spectrum of the horizontal component can be calculated by

$$
A_{\mathrm{H}}(f)=\sqrt{\left(A_{\mathrm{NS}}(f)\right)^{2}+\left(A_{\mathrm{EW}}(f)\right)^{2}},
$$




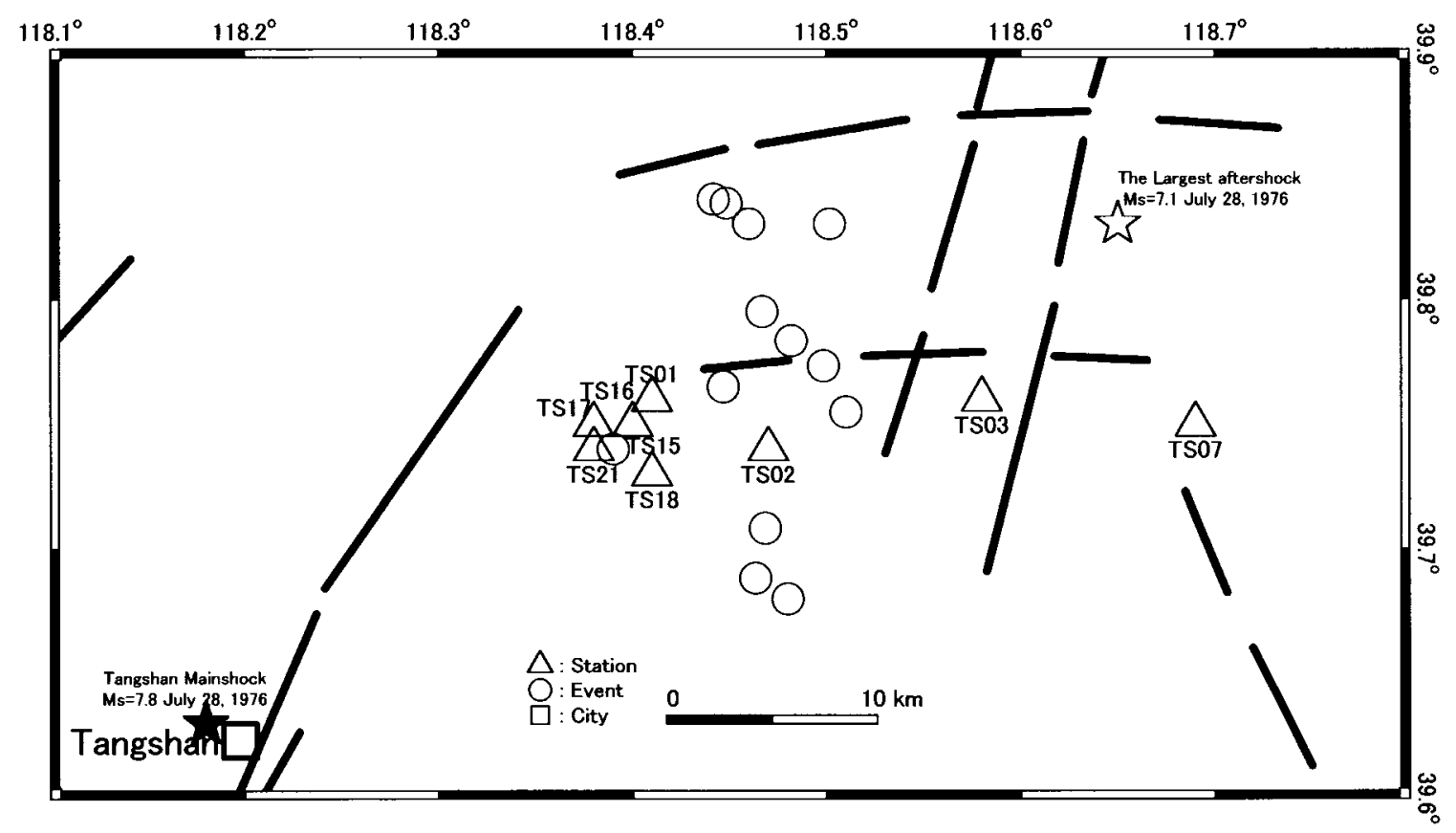

Figure 2. Distribution of nine stations (triangles) and 13 events (circles). Stations, triangles; event epicenters, circles; filled star, mainshock (Tangshan earthquake, $M_{\mathrm{s}}$ 7.8, 28 July 1976); open star, largest aftershock (Luanxian earthquake, $M_{\mathrm{s}} 7.1,28$ July 1976); heavy lines, faults.

Table 1

Stations and Site Conditions

\begin{tabular}{lcccccc}
\hline No. & Code & Site & Latitude & Longitude & Elevation $(\mathrm{m})$ & Geology Condition \\
\hline 1 & TS01 & Ground/rock & $39^{\circ} 45.6^{\prime}$ & $118^{\circ} 24.4^{\prime}$ & 76 & Outcrop rock \\
2 & TS02 & Ground/soil & $39^{\circ} 44.5^{\prime}$ & $118^{\circ} 28.5^{\prime}$ & 40 & $14 \mathrm{~m}$ soil and sand \\
3 & TS03 & Ground/soil & $39^{\circ} 45.3^{\prime}$ & $118^{\circ} 34.6^{\prime}$ & 45 & $43 \mathrm{~m}$ soil layers \\
4 & TS07 & Ground/soil & $39^{\circ} 44.9^{\prime}$ & $118^{\circ} 41.4^{\prime}$ & 45 & $52 \mathrm{~m}$ soil layers \\
5 & TS15 & Tunnel/rock & $39^{\circ} 44.8^{\prime}$ & $118^{\circ} 23.8^{\prime}$ & -822 & Rock in coal bed \\
6 & TS16 & Ground/soil & $39^{\circ} 44.9^{\prime}$ & $118^{\circ} 24.0^{\prime}$ & 48 & 3 m sand and clay \\
7 & TS17 & Ground/soil & $39^{\circ} 44.8^{\prime}$ & $118^{\circ} 22.7^{\prime}$ & 38 & $12 \mathrm{~m}$ sand and clay \\
8 & TS18 & Ground/soil & $39^{\circ} 43.7^{\prime}$ & $118^{\circ} 24.6^{\prime}$ & 47 & $10 \mathrm{~m}$ sand and clay \\
9 & TS21 & Ground/soil & $39^{\circ} 44.7^{\prime}$ & $118^{\circ} 22.7^{\prime}$ & 38 & $12 \mathrm{~m}$ sand and clay \\
\hline
\end{tabular}

where $f$ is the frequency, $A_{\mathrm{NS}}$ and $A_{\mathrm{EW}}$ represent the northsouth and east-west components of the accelerogram, and $A_{\mathrm{H}}$ is the horizontal component. For all spectra, smoothing was performed using a Hanning window with a bandwidth of $0.5 \mathrm{~Hz}$. Figure 3 shows an example of records simultaneously observed at the surface rock site station TS01 and the underground rock site station TS15. This figure also shows the spectra of the $S$-wave parts and the noise parts before the $P$-wave arrivals.

\section{Linear Inversion}

Assuming that $S$ waves are radiated spherically from a point source, the Fourier amplitude spectrum of the observed $S$ wave can be expressed as follows:

$$
Q_{i j}(f)=S_{i}(f) G_{i j}(f) R_{i j}^{-1} \exp \left(-\frac{\pi R_{i j} f}{Q_{\mathrm{s}}(f) V_{\mathrm{s}}}\right),
$$

where $O_{i j}(f)$ is the $S$-wave Fourier amplitude spectrum of the $i$ th event recorded at the $j$ th station, $S_{i}(f)$ is the source term for the $i$ th event, $G_{i j}(f)$ and $R_{i j}$ are the site term and the hypocentral distance for the $i$ th event and the $j$ th station, respectively, and $Q_{\mathrm{s}}(f)$ and $V_{\mathrm{s}}$ denote the average quality factor and the average velocity of the $S$ waves in the medium, respectively. Under the condition that a data set consists of many earthquakes with a wide epicentral distribution, the site effect can be assumed to be independent of the azimuth of $S$-wave propagation from the epicenter to the station and the incidence angle of the $S$ wave to the station by averaging 
Table 2

Parameters for Analyzed Earthquakes and Recording Stations

\begin{tabular}{|c|c|c|c|c|c|c|c|c|c|c|c|c|c|c|c|}
\hline \multirow[b]{2}{*}{ No. } & \multirow[b]{2}{*}{ Code } & \multirow{2}{*}{$\begin{array}{c}\text { Date } \\
(\mathrm{mm} / \mathrm{dd} / \mathrm{yy})\end{array}$} & \multirow[b]{2}{*}{$M_{\mathrm{L}}$} & \multirow{2}{*}{$\begin{array}{l}\text { Latitude } \\
\left({ }^{\circ}\right)\end{array}$} & \multirow{2}{*}{$\begin{array}{l}\text { Longitude } \\
\left({ }^{\circ}\right)\end{array}$} & \multirow{2}{*}{$\begin{array}{c}\text { Depth } \\
(\mathrm{km})\end{array}$} & \multicolumn{9}{|c|}{ Station } \\
\hline & & & & & & & TS01 & TS02 & $\mathrm{TS} 03$ & TS07 & TS15 & TS16 & TS17 & TS18 & $\mathrm{TS} 21$ \\
\hline 1 & 83077 & $08 / 08 / 83$ & 2.9 & 39.71 & 118.47 & 4.4 & $*$ & & * & & * & & & $*$ & \\
\hline 2 & 83079 & $08 / 09 / 83$ & 3.8 & 39.68 & 118.48 & 9.2 & * & * & * & & * & * & & * & \\
\hline 3 & 83081 & $08 / 13 / 83$ & 3.6 & 39.69 & 118.46 & 6.9 & * & & * & & * & * & * & * & \\
\hline 4 & 83099 & $09 / 24 / 83$ & 3.5 & 39.77 & 118.50 & 7.2 & $*$ & $*$ & $*$ & $*$ & $*$ & $*$ & $*$ & $*$ & \\
\hline 5 & 83103 & $09 / 26 / 83$ & 3.3 & 39.77 & 118.45 & 7.7 & $*$ & $*$ & & & $*$ & & $*$ & $*$ & \\
\hline 6 & 83104 & $09 / 26 / 83$ & 4.2 & 39.74 & 118.39 & 10 & $*$ & $*$ & $*$ & $*$ & $*$ & $*$ & $*$ & $*$ & \\
\hline 7 & 83108 & $10 / 02 / 83$ & 2.8 & 39.80 & 118.47 & 4.1 & * & * & & & * & & * & * & \\
\hline 8 & 84029 & $02 / 16 / 84$ & 3.7 & 39.76 & 118.51 & 8.2 & & $*$ & $*$ & $*$ & $*$ & & & & \\
\hline 9 & 84117 & $11 / 05 / 84$ & 2.9 & 39.78 & 118.48 & 7.7 & * & * & * & $*$ & $*$ & $*$ & & & \\
\hline 10 & 84132 & $12 / 10 / 84$ & 3.5 & 39.83 & 118.50 & 5.8 & $*$ & $*$ & $*$ & $*$ & $*$ & & & $*$ & $*$ \\
\hline 11 & 84138 & $12 / 11 / 84$ & 3.8 & 39.84 & 118.46 & 8.2 & * & $*$ & * & $*$ & $*$ & & & * & * \\
\hline 12 & 84139 & $12 / 11 / 84$ & 3.9 & 39.84 & 118.45 & 9.6 & $*$ & $*$ & $*$ & & $*$ & & & $*$ & $*$ \\
\hline 13 & 84142 & $12 / 11 / 84$ & 3.5 & 39.84 & 118.44 & 6.7 & * & $*$ & * & $*$ & $*$ & & & $*$ & * \\
\hline
\end{tabular}

An asterisk indicates that the station recorded the corresponding earthquake.
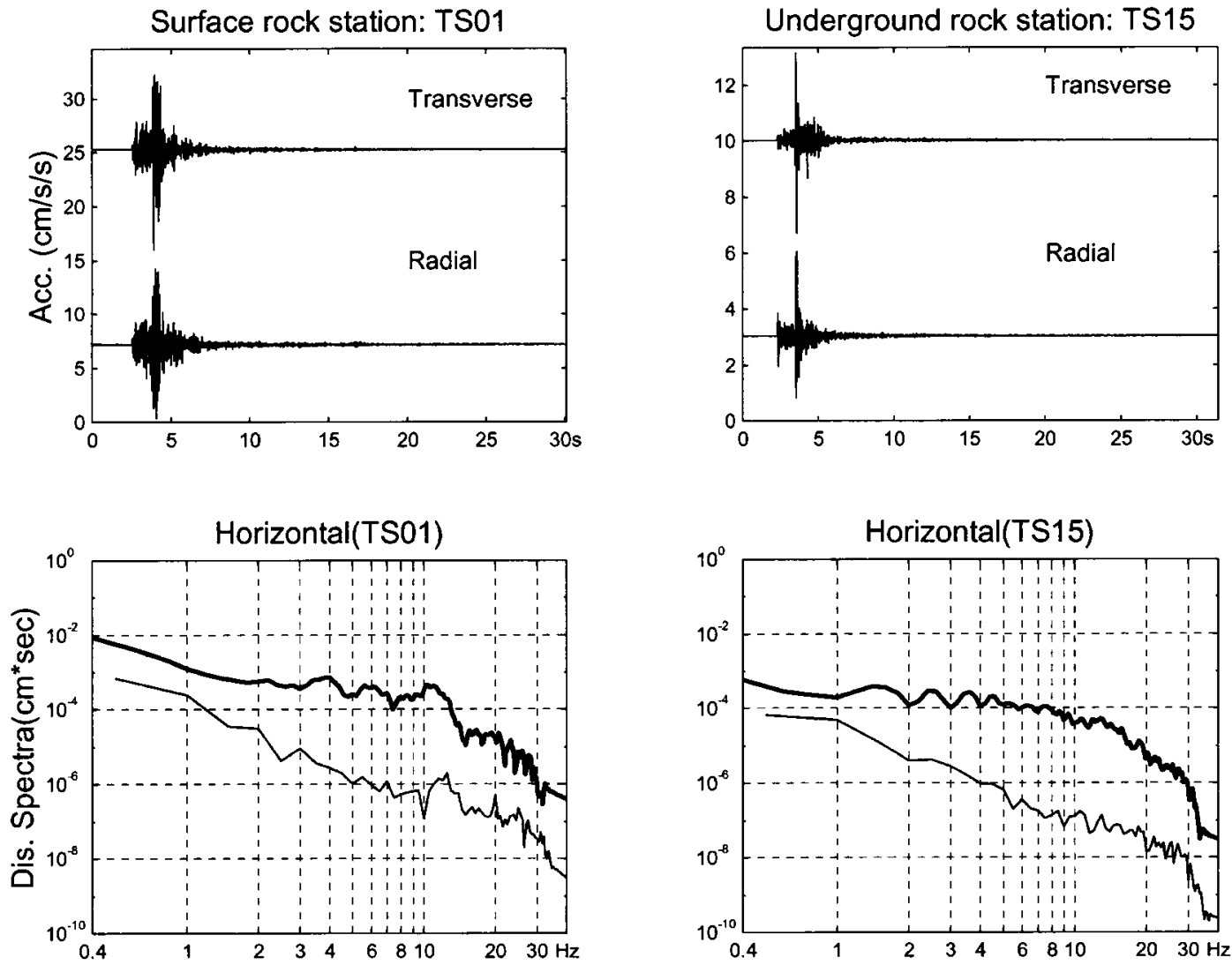

Figure 3. An example of records observed simultaneously at the surface rock site station TS01 and the underground rock site station TS15 (upper) and the corresponding $S$-wave (thick lines) and noise (thin lines) spectra before the $P$-wave arrival (lower).

the results over many earthquakes. In this case, the result of linear inversion using many earthquakes is expected to give the average site effect over many earthquakes. In equation (2), therefore, $G_{i j}(f)$ can be expressed as $G_{j}(f)$, and equation (2) can be rewritten as follows (Iwata and Irikura, 1989; Boatwright et al., 1991; Hartzell, 1992):

$$
O_{i j}(f)=S_{i}(f) G_{j}(f) R_{i j}^{-1} \exp \left(-\frac{\pi R_{i j} f}{Q_{\mathrm{s}}(f) V_{\mathrm{s}}}\right)
$$

The spectral ratio between the $j$ th station and the reference station is obtained by 


$$
\frac{O_{i j}(f)}{O_{i \mathrm{r}}(f)}=\frac{G_{j}(f)}{G_{\mathrm{r}}(f)} \frac{R_{i \mathrm{r}}}{R_{i j}} \exp \left(-\frac{\pi\left(R_{i j}-R_{i \mathrm{r}}\right) f}{Q_{\mathrm{s}}(f) V_{\mathrm{s}}}\right),
$$

where the subscript "r" denotes the reference station. By taking the logarithm, equation (4) can be rewritten at a fixed frequency as

$$
g_{j}+\pi f\left(R_{i \mathrm{r}}-R_{i j}\right) / Q_{\mathrm{s}}(f) V_{\mathrm{s}}=r_{i j}+o_{i j} .
$$

Here, $g_{j}=\ln \left(\frac{G_{j}(f)}{G_{\mathrm{r}}(f)}\right), o_{i j}=\ln \left(\frac{O_{i j}}{O_{i \mathrm{r}}}\right)$, and $r_{i j}=\ln \left(\frac{R_{i j}}{R_{i \mathrm{r}}}\right)$.

Denoting $\alpha_{i j}=\pi f\left(R_{i \mathrm{r}}-R_{i j}\right) / V_{\mathrm{s}}$ and $d_{i j}=o_{i j}+r_{i j}$, equation (5) becomes

$$
g_{j}+\alpha_{i j} Q_{\mathrm{s}}^{-1}=d_{i j} .
$$

For all events and all stations, equation (6) can be expressed in matrix form by

$$
\mathbf{G m}=\mathbf{d},
$$

where $\mathbf{m}$ is a vector in the model space, $\mathbf{d}$ is a vector in the data space, and $\mathbf{G}$ is a matrix relating $\mathbf{m}$ to $\mathbf{d}$. Figure 4 illustrates the matrix given in equation (7) in detail. The unknown parameters of the model space are the site effect relative to the reference site, $g_{j}$, and the reciprocal of the average quality factor of the medium, $Q_{\mathrm{s}}^{-1}$, for each frequency. The site effect of the reference station is constrained to 1 , that is, $g_{\mathrm{r}}(f)=0$ or $G_{\mathrm{r}}(f)=1.0$. The inversion was executed by finding a solution of $\mathbf{m}$ that minimized the prediction error, $|\mathbf{G m}-\mathbf{d}|^{2}$. A least-squares solution was obtained using the singular value decomposition method (Lawson and Hanson, 1974). The standard deviations of the model parameters were estimated from diagonal elements of the covariance matrix (Menke, 1989) according to

$$
[\operatorname{cov} m]=\sigma_{\mathrm{d}}^{2}\left[G^{\mathrm{T}} G\right]^{-1},
$$

where $\sigma_{\mathrm{d}}^{2}$ is the variance of the data.

\section{Reference-Independent Technique Using GA}

A GA technique was used to determine the absolute site responses and source parameters simultaneously without reference-site information. The GA is a search algorithm based on the mechanisms of natural selection and natural genetics, a survival-of-the-fittest strategy. The procedure for the present reference-independent technique is similar to that of Moya et al. (2000) and is based on the assumption that the site effect of a station should be independent of the characteristics of an earthquake. In this case, an individual of the GA consists of two parameters of the $\omega$-squared source model: the flat level of the displacement source spectrum, $\Omega_{0}$, and its corresponding corner frequency, $f_{\mathrm{c}}$.

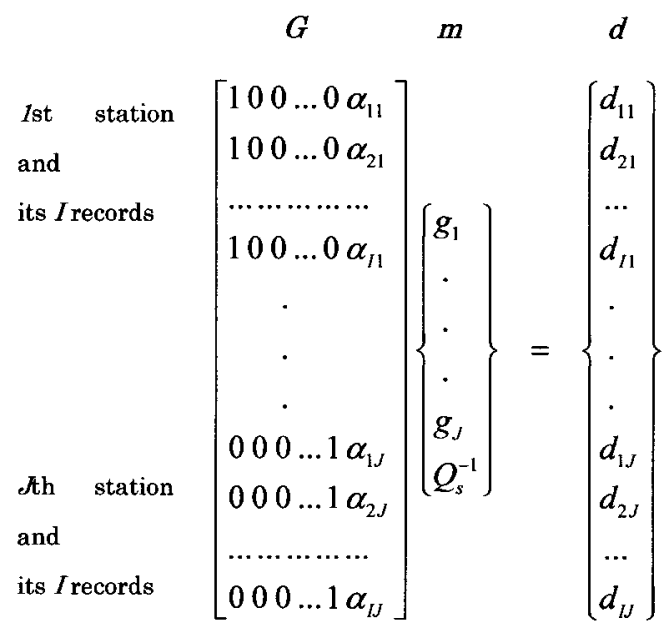

Figure 4. Details of the matrix given in equation (7). The subscripts $I$ and $J$ denote the total number of events and stations, respectively.

Figure 5 shows the GA inversion process. Using a frequency-dependent $Q_{\mathrm{s}}$ value $\left[Q_{\mathrm{s}}(f)\right]$ obtained in advance by linear inversion, a $V_{\mathrm{s}}$ value $(=3200 \mathrm{~m} / \mathrm{sec})$, and a hypocentral distance, $R_{i j}$, the observed spectra are corrected for wave attenuation along the propagation path and geometrical spreading of the wavefront. The corrected spectrum is expressed as

$$
O_{i j}^{\text {corr }}(f)=O_{i j}(f) R_{i j} \exp \left(\pi R_{i j} f / Q_{\mathrm{s}}(f) V_{\mathrm{s}}\right) .
$$

Substituting equation (2) into equation (9) and solving for the site term, we obtain

$$
G_{i j}(f)=O_{i j}^{\text {corr }}(f) / S_{\mathrm{i}}(f) .
$$

To estimate the site effect, $G_{i j}(f)$, the $\omega$-squared source model is used, in which the displacement source spectrum is given by

$$
S_{i}(f)=\frac{\Omega_{i}}{1+\left(f / f_{\mathrm{c} i}\right)^{2}},
$$

where $\Omega_{i}$ is the flat level of the source spectrum for the $i$ th event and $f_{c i}$ is the corner frequency of the $i$ th event. In the inversion process, the GA produces an $\Omega$ and $f_{\mathrm{c}}$ for every earthquake. With this information, the mean and standard deviation of the site effects for each station can be calculated. If the standard deviation is large, the GA produces new models for the $\Omega$ and $f_{\mathrm{c}}$ of every earthquake so as to reduce the standard deviation. This inversion then continues until the standard deviation of the site effects becomes minimal for every station. To perform this process, an evaluation function ( func $_{\text {eval }}$ ) is introduced as a reference for judging whether the standard deviation of the site effect for each station calculated from the source models proposed by the 


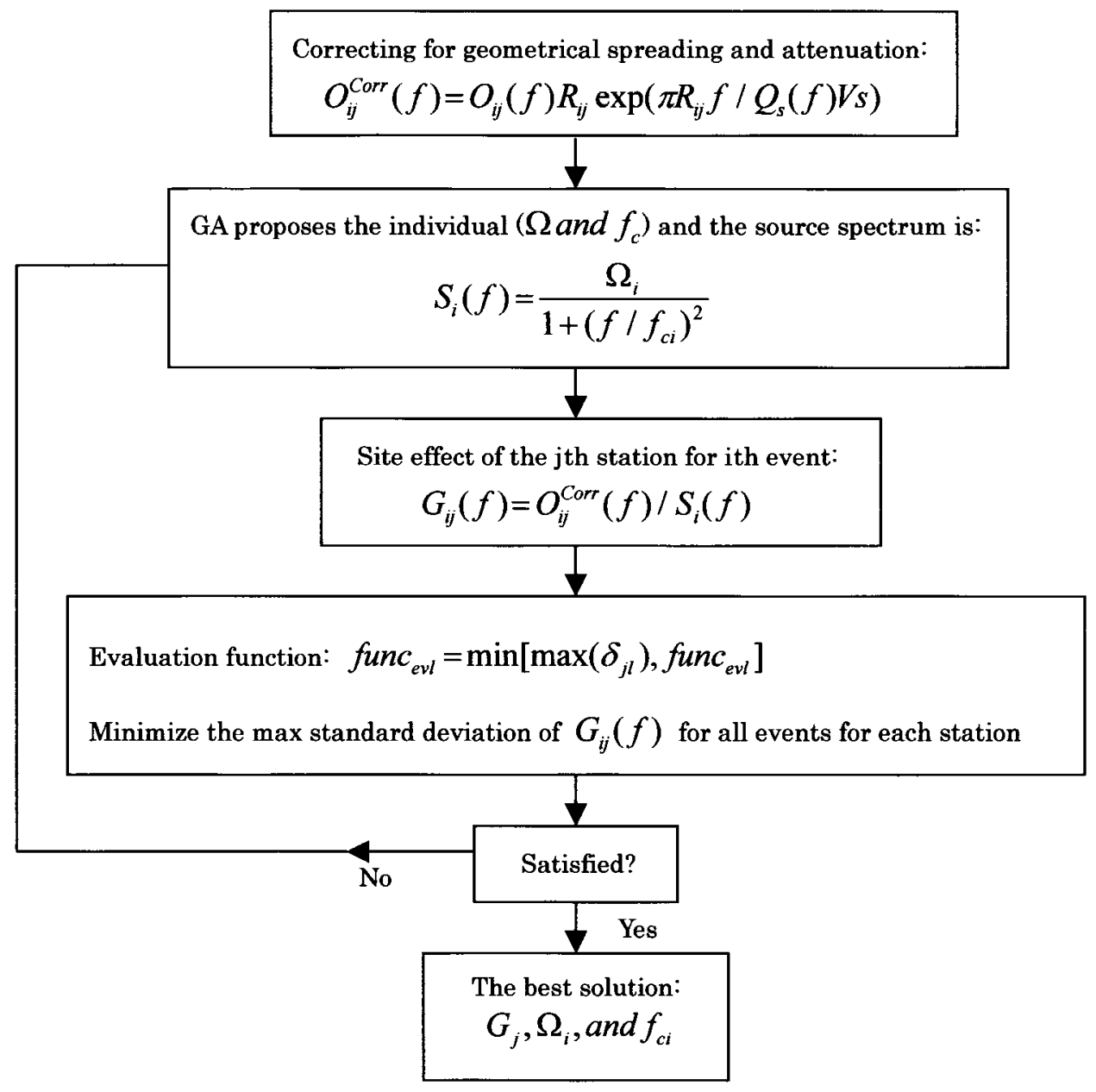

Figure 5. Diagram of the reference-independent technique of estimating site effects.

GA is less than that from the preceding source models. The normalized standard deviation of the site effects for the $j$ th station is expressed as

$$
\delta_{j}(f)=\sigma\left[G_{i j}(f)\right] / G_{j}(f),
$$

where $\sigma$ denotes the standard deviation and $G_{j}(f)$ is the average of all site effects for the $j$ th station given by

$$
G_{j}(f)=\sum_{i=1}^{n} G_{i j}(f) / n
$$

for $n$ earthquakes. Expressing the normalized standard deviation of the site effect of the $l$ th frequency for the $j$ th station by $\delta_{j l}$, the evaluation function is defined as

$$
\text { func }_{\mathrm{evl}}=\min \left[\max \left(\delta_{j l}\right), \text { func }_{\mathrm{evl}}\right] .
$$

The evaluation function is reset every iteration by comparing the maximum value of $\delta_{j l}$ for all frequencies for every station with the evaluation function in the preceding iteration. The inversion continues by selecting different values of $\Omega$ and $f_{\mathrm{c}}$ for each earthquake until a certain number of iterations is reached and func ${ }_{\text {eval }}$ is at a minimum. In the present case, 200 iterations were performed. At the end of the inversion, the optimal values of $\Omega_{i}$ and $f_{\mathrm{c} i}$ and the corresponding site effect, $G_{j}(f)$, are produced as the output of the GA.

In searching for the optimal values of $\Omega_{i}$ and $f_{\mathrm{c} i}$ using the GA, exact initial values of the two parameters are not required. Instead, the ranges to search for them are defined. The upper limit for $\Omega_{i}$ was set based on the flat level of $O_{i j}^{\text {corr }}$ at lower frequencies, and the lower limit was set at onethird of the upper limit value. For $f_{\mathrm{c} i}$, a search range is set in consideration of the magnitude of earthquakes: for $M_{\mathrm{L}}$ $<3.0$ earthquakes, $f_{\mathrm{ci}}$ is set in the range $2-10 \mathrm{~Hz}$, and for $M_{\mathrm{L}}>3.0, f_{\mathrm{c} i}$ is set in the range $0.3-8 \mathrm{~Hz}$. In this way, the optimal solution for $\Omega_{i}, f_{\mathrm{c} i}$, and the corresponding site effect, $G_{j}(f)$, were determined simultaneously. It should be noted that the site effects obtained are absolute site effects that are independent of any reference site, dependent only on the seismic source model. 

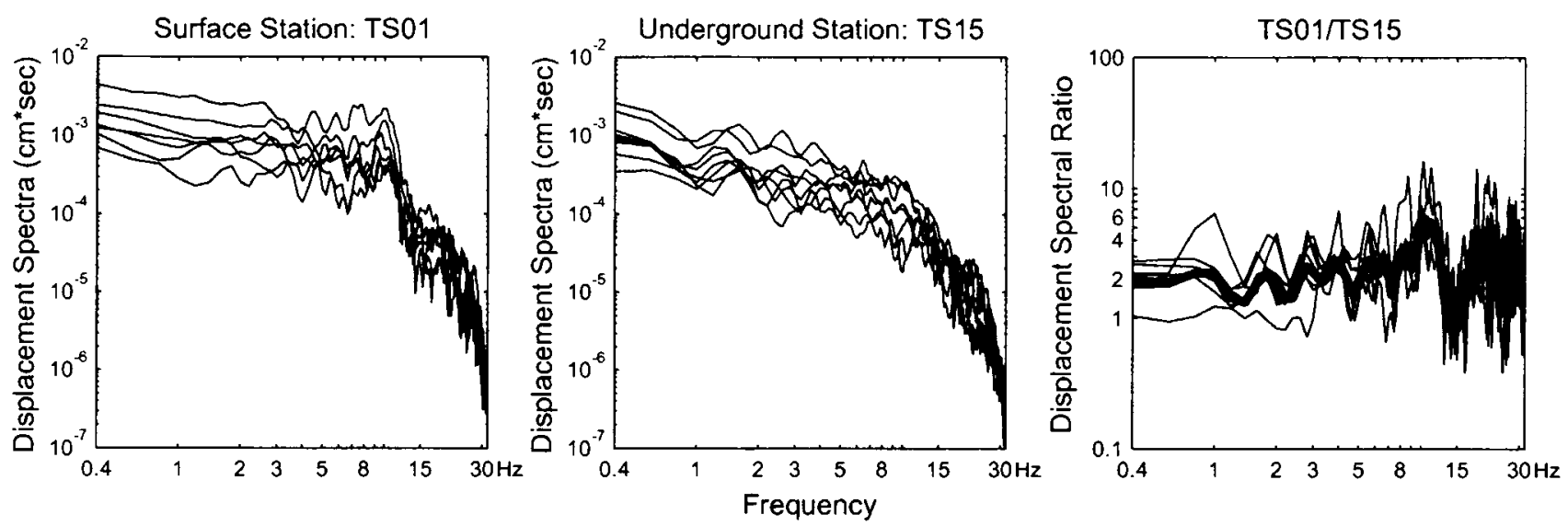

Figure 6. Stack of spectra of TS01 and TS15 and the ratio TS01/TS15. The thin line is the ratio of each event, and the thick line is the average value.

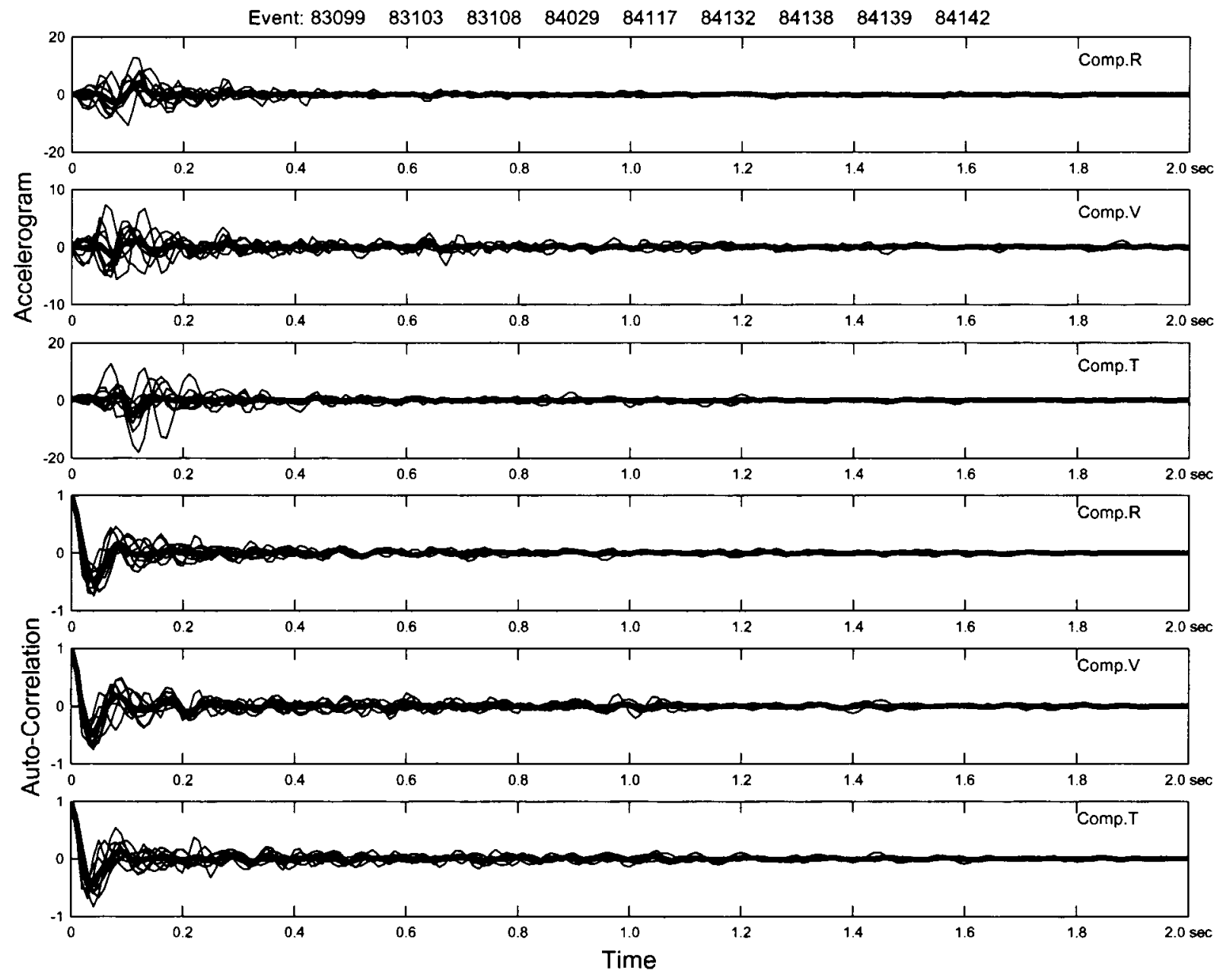

Figure 7. Stack of accelerograms (upper three) and autocorrelations (lower three) for nine events. The analysis interval is $2 \mathrm{sec}$ from the $S$-wave onset. The thin lines are the results for each event, and the thick lines are the average values. 


\section{Results}

Linear Inversion for $S$ Waves

Destructive Interference. When using an underground station as the reference site, the effect of waves reflected from the surface needs to be taken into account. The underground motions may have significant notches around particular frequencies related to destructive interference between the upcoming and downgoing waves (Steidl et al., 1996). Theoretical prediction of the frequency of the first mode of the notch in the spectral ratio of surface records to the underground record can be estimated by the formula

$$
f=V_{\mathrm{s}} / 4 H,
$$

where $H$ is the depth of the underground station from the surface. In this case, $H$ is about $822 \mathrm{~m}$ and $V_{\mathrm{s}}$ is about 2000 $\mathrm{m} / \mathrm{sec}$, giving a notch frequency of $f=0.6 \mathrm{~Hz}$. However, it is expected that the large depth of the underground station will suppress the effect of reflections in the underground data because of high attenuation in the near-surface materials.

The effect of destructive interference on the recorded underground motion was then examined. The ratio of displacement spectra between the surface and the underground station was taken using $15 \mathrm{sec}$ of $S$-wave data, as shown in Figure 6 . The spectral ratios in the frequency range from 0.4 to $1 \mathrm{~Hz}$ do not contain a notch. If the underground data includes an obvious reflection, a stack of records with nearly the same azimuth should reveal the reflection phase at some delay time (about $0.8 \mathrm{sec}$ in this case) following the direct $S$ waves, and the autocorrelation of the records should become large at the same delay time. The waveforms for $2 \mathrm{sec}$ from the $S$-wave onset for nine events with nearly the same azimuth at station TS15 are shown in Figure 7. Again, there is no obvious evidence of reflections in the records at the underground station, indicating that waves reflected from the surface contribute very little to the data obtained at the present underground station.

Effect of Propagation Path $\left(\mathrm{Q}_{\mathrm{s}}\right)$. Figure 8 shows the frequency-dependent $S$-wave attenuation $\left(Q_{\mathrm{s}}^{-1}\right)$ determined from the $S$-wave inversion. Generally, $Q_{\mathrm{s}}$ is the quality factor corresponding to the propagation path from the source to the station. Only six stations (TS01, TS02, TS03, TS07, TS15, and TS18), including the underground station TS15, were used for this calculation. This group of stations includes three representative stations (TS01, TS15, and TS18) from a larger number of relatively crowded stations considering the similarity of hypocentral distances. As the stations and the epicenters are located in a limited area and the events occurred at depths of 4-10 km, the $Q_{\mathrm{s}}$ in this case represents the quality factor of the upper crust in this area. Assuming a functional form $Q_{\mathrm{s}}=\alpha f^{\beta}$ to fit the $Q_{\mathrm{s}}$ values, a frequencydependent value of $29 f^{0.9}$ is obtained, which gives a very low value of $Q_{\mathrm{s}}$, corresponding as expected to a high $S$-wave

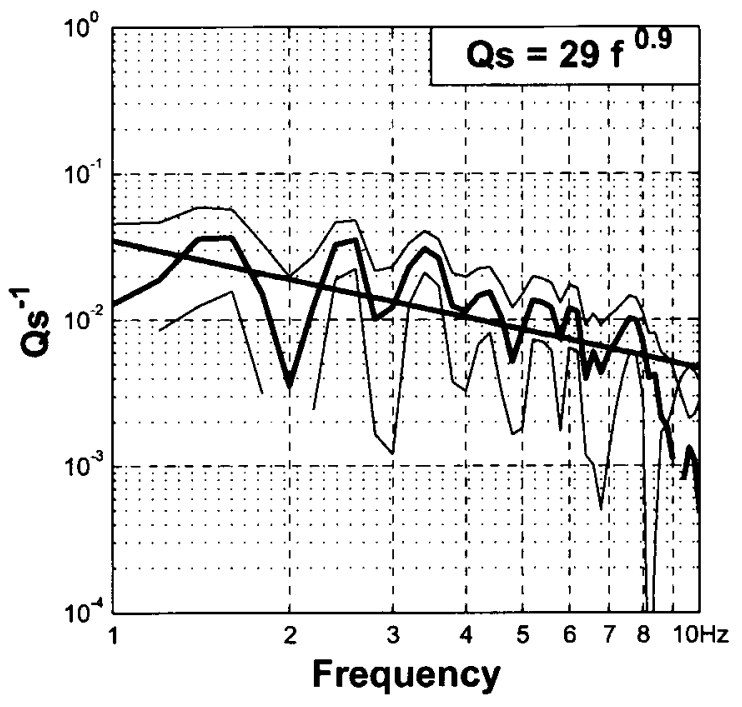

Figure 8. Frequency-dependent $S$-wave attenuation, $Q_{\mathrm{s}}^{-1}$. The thick curve is the $Q_{\mathrm{s}}^{-1}$ value from the inversion method, and the thin curves are the standard deviation. The line is the mean value approximated by the relation $Q_{\mathrm{s}}=\alpha f^{\beta}(\alpha=29, \beta=0.9)$.

attenuation. It is suggested that this result reflects a high seismic attenuation in the fractured source area.

Relative Site Amplification. Figure 9 shows the site effects determined from the linear inversion of $S$ waves using the underground rock site as the reference site. The stations located on thin sediments of about $10 \mathrm{~m}$ thick (TS02, TS16, TS17, TS18, and TS21) exhibit amplification effects at frequencies from 1 to $10 \mathrm{~Hz}$ and deamplification for frequencies higher than $10 \mathrm{~Hz}$. All of these stations have a clear dominant frequency: $4.3 \mathrm{~Hz}$ for TS02, $6 \mathrm{~Hz}$ for TS16, 5.8 $\mathrm{Hz}$ for TS17, $9 \mathrm{~Hz}$ for TS18, and $6.5 \mathrm{~Hz}$ for TS21. The amplification factors at these dominant frequencies are about 17 for TS02, 8.5 for TS16, 18 for TS17, 20 for TS18, and 5 for TS21.

The stations on thick sediments of about $50 \mathrm{~m}$ thick (TS03 and TS07) exhibit amplification over a broad frequency range from 1 to $20 \mathrm{~Hz}$, but do not exhibit obvious dominant peaks. The amplification at TS03 is about 10 between 2 and $7 \mathrm{~Hz}$, and the amplification at TS07 is about 5, peaking at $7 \mathrm{~Hz}$ but with a much flatter response than other sites between 1 and $10 \mathrm{~Hz}$.

Note that the site response at the surface rock site station TS01 deviates significantly from the assumption that the site effect at a rock site is flat with respect to frequency, with a nominal amplification factor of 2 at the free surface. In the present case, the motions at the surface rock site were significantly amplified, particularly at high frequencies. To examine the effect of this deviation from the assumption, the responses of each site were recalculated for the case in which the surface rock site was the reference site and its site effect was constrained to 2 for all frequencies. The results are 

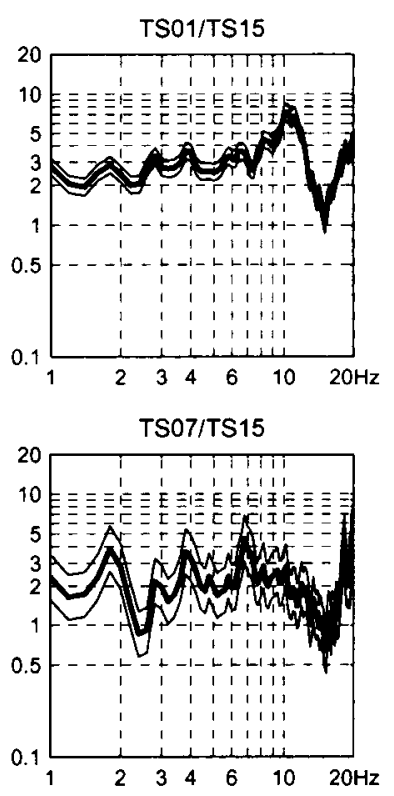

TS17/TS15

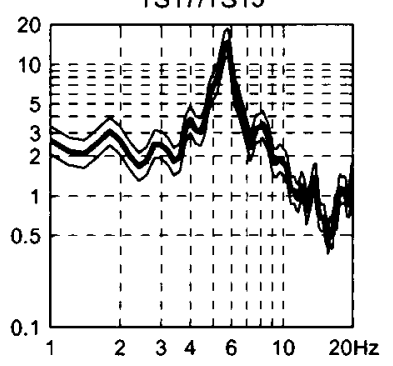

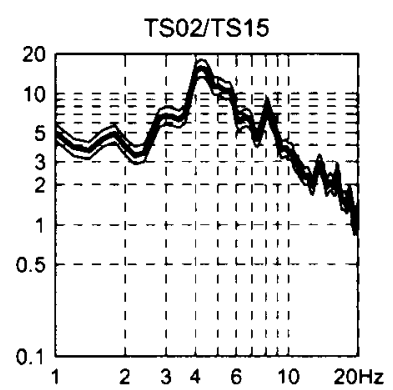

TS15/TS15
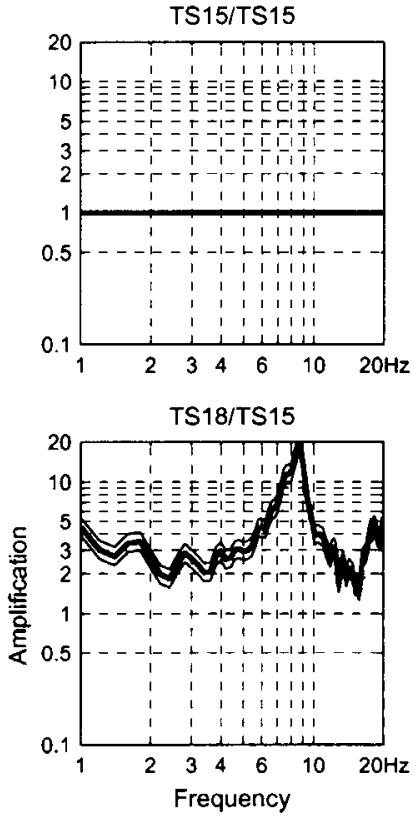

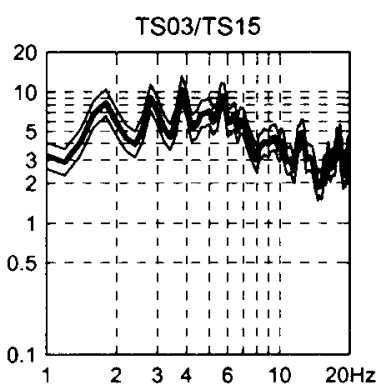

TS16/TS15

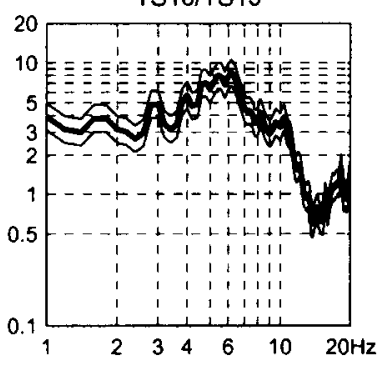

TS21/TS15

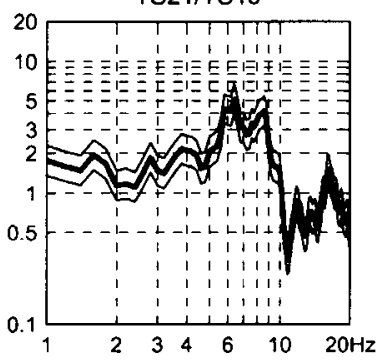

Figure 9. Site effects using the underground station (TS15) as the reference site. The thick lines are the mean values of the relative site effects, and the thin lines are their standard deviation.

shown in Figure 10 along with the result for the underground reference station TS15 and the ratio between the two series of results. The site amplification of the surface station of 24 between 6 and $10 \mathrm{~Hz}$ will lead to an underestimation of the seismic hazard when such a reference site is selected. At low frequencies, however, the site effect at TS01 is much flatter, and the two sets of results do not differ appreciably. Therefore, the common assumption that the ground motion of a nearby rock site is an accurate reference of input motion to a soil site is only valid at frequencies below $6 \mathrm{~Hz}$, at least in the present case. The main implication of this finding is that surface reference stations must be selected carefully for seismic hazard analysis and that, in general, underground rock sites are a better reference than surface rock sites.

\section{Site Effects by the Reference-Independent Technique}

Figure 11 shows the site responses calculated by the reference-independent technique using the GA, together with the results of linear inversion using the underground station as the reference site. The site amplifications produced by the two methods agree very well, particularly at frequencies from 1 to $15 \mathrm{~Hz}$. Furthermore, we must note that TS15 is located in the tunnel of a mine. The site response of TS15 of nearly 1 at frequencies from 1 to $15 \mathrm{~Hz}$ can be seen in the reference-independent result. This is consistent with the theoretical site effect of 1 for an underground site. Thus, these results indicate that this reference-independent technique provides accurate absolute site responses for the rock and soil sites used in this study and that the underground rock site performs as an accurate reference site.

\section{Discussion}

The site effects obtained in this study reveal that surface rock sites do not have a flat response as previously thought and in fact will have characteristic frequency-dependent site effects. This supports other reports (Steidl et al., 1996; Boore and Joyner, 1997) that the common assumption that a nearby rock site represents the reference motion for a soil site needs to be questioned. It was shown in the present study that an 
TS01
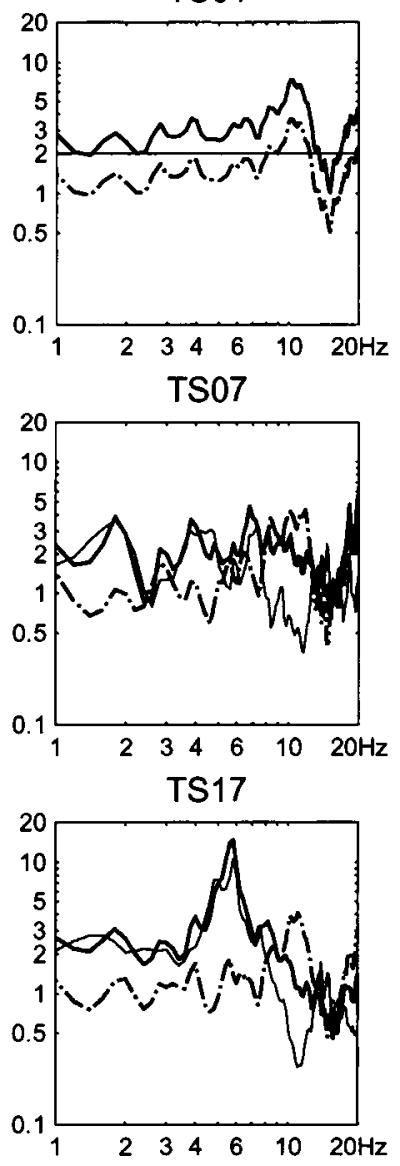

TS02
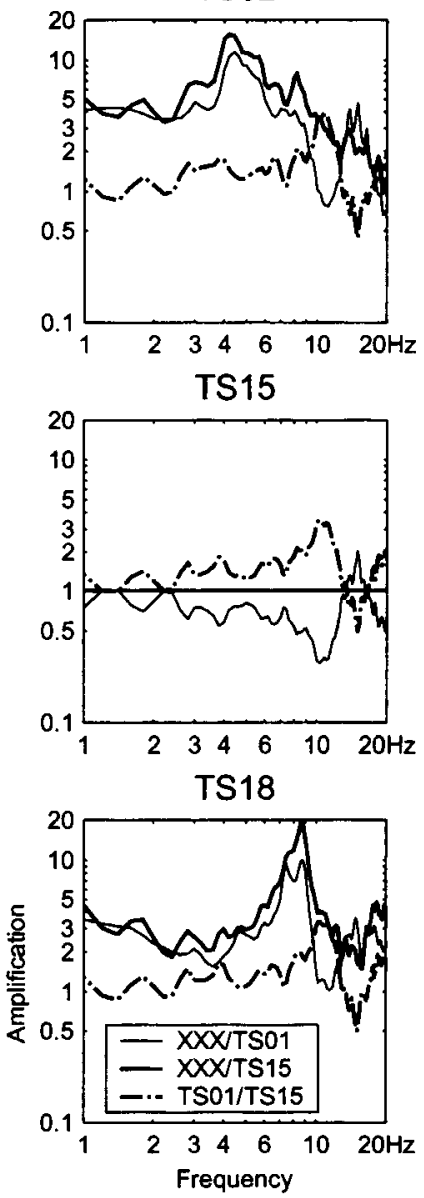

TS03
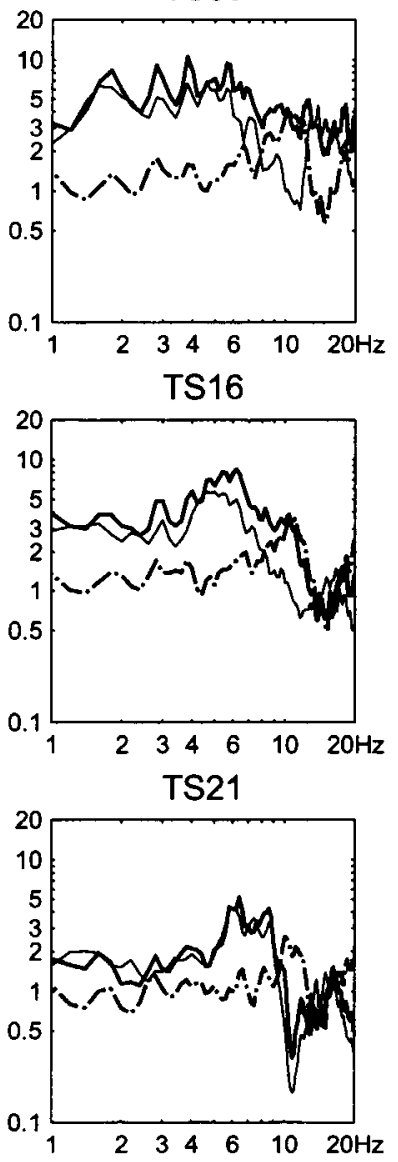

Figure 10. Site effects using the surface rock site (TS01, thin lines) and the underground rock site (TS15, thick lines) as reference sites. The dashed-dotted lines represent the ratio TS01/TS15.

underground or borehole rock site represents a very accurate reference for seismic hazard analysis when the destructive interference of reflection from the surface is taken into account.

Linear inversion as a reference-dependent approach does not treat the source model directly. By removing the need for a reference site, the proposed reference-independent method produces results related to the source model alone. If the source model accurately reflects the real source mechanism, the results of the reference-independent technique will represent the true absolute site amplifications. As shown in equation (10), however, the results of the referenceindependent technique may be implicitly affected by a tradeoff between the site and source effects if source spectra are assumed. In the present case, the effect of the trade-off was examined by comparing the reference-free results with the results using the underground rock site and surface rock site as references. The findings match well with theoretical predictions, indicating that the reference-independent technique assuming the $\omega$-squared source model is not appreciably af- fected by the trade-off between the site effect and the source effect. Therefore, it is thought that the reference-independent technique produced accurate absolute site responses for the rock and soil sites used in this study.

In this study, the $\omega$-squared source model was assumed, which is suitable for evaluating site effects in response to small events. Although this source model is widely applied to small events, it is necessary to examine whether the source model does indeed match the actual events used for analysis in this study. Figure 12 shows the average observed displacement source spectra for all 13 events used in this study and the corresponding best-fit models of the referenceindependent technique based on Brune's $\omega$-squared source model. The results are very consistent up to about $15 \mathrm{~Hz}$, demonstrating that the assumption of an $\omega$-squared source model is valid for the earthquakes analyzed in this study. The discrepancies at higher frequencies should be discussed associated with either $f_{\max }$ (Hanks, 1982) in the source model theory or kappa (Anderson and Hough, 1984) of a parameter for seismic attenuation due to near-surface materials. 
TS01

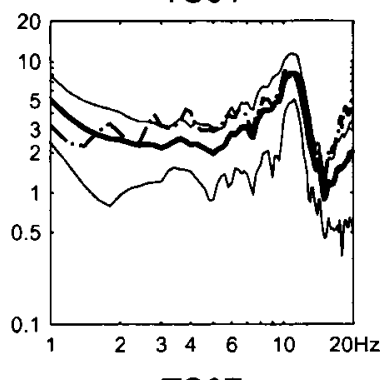

TS07

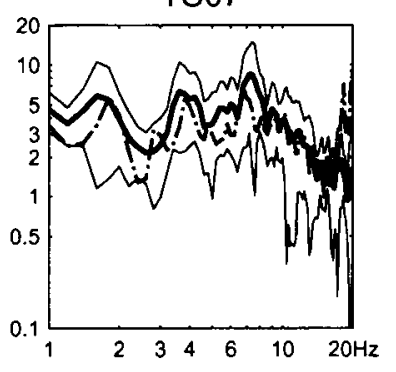

TS17

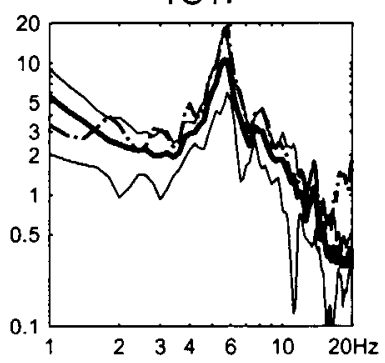

TS02

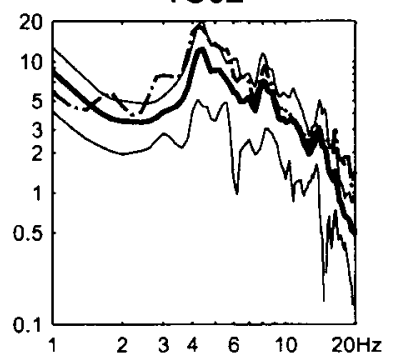

TS15
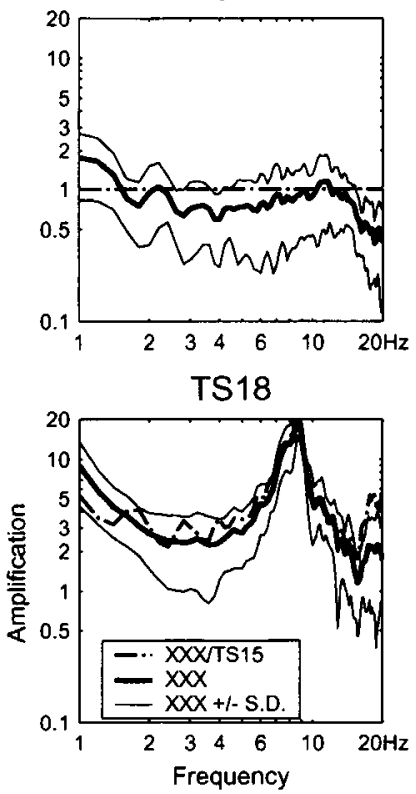

TS03

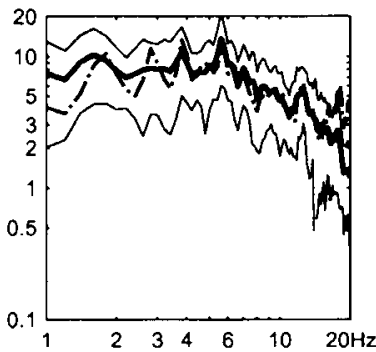

TS16

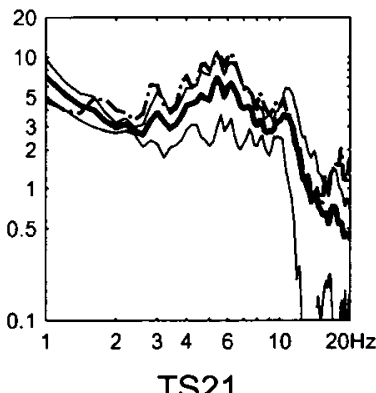

TS21

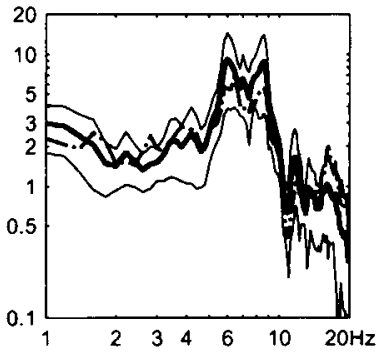

Figure 11. Site effects by the reference-independent technique compared to results using the underground rock site (TS15) as a reference (thin lines). The thick lines are the results of the reference-independent technique, and the thin lines are the standard deviation. The dashed-dotted lines represent the results obtained using the underground rock site (TS15) as the reference.

\section{Conclusions}

Site amplification was analyzed for the Tangshan area of China using strong motion data from aftershocks of the 1976 Tangshan earthquake. An underground rock site station and a surface rock site station were compared as reference sites to separate the source, propagation path, and site effects simultaneously by linear inversion, and a referenceindependent technique assuming Brune's $\omega$-squared source model was introduced as an alternative method of determining site effects.

It was found that the $S$-wave quality factor is approximated by the relation $Q_{\mathrm{s}}=29 f^{0.9}$ in the frequency range 1$10 \mathrm{~Hz}$. This result represents the $S$-wave quality factor of the upper crust in the limited area studied and suggests that the fractured source area is characterized by high seismic attenuation.

Furthermore, it was found that the surface rock site ref- erence station in this study does not have a flat response in the frequency range of engineering interest. In the present case, the surface rock site exhibited characteristic frequencydependant amplification of 2-4 at $6-10 \mathrm{~Hz}$. This bias will lead to underestimations in seismic hazard prediction. Thus, the common assumption that the ground motion of a nearby rock site represents the reference motion for a soil site does not hold for frequencies higher than about $6 \mathrm{~Hz}$, at least in the present case.

The site effects determined by the reference-independent technique agree very well with those obtained using the underground station as a reference for most of the rock and soil sites. Furthermore, the method revealed that the underground rock site has a nearly flat response of 1 between 1 and $15 \mathrm{~Hz}$. It was also shown that the theoretical source spectrum obtained by the reference-independent technique is consistent with the observations. These results indicate that the underground rock site station performed as a much 

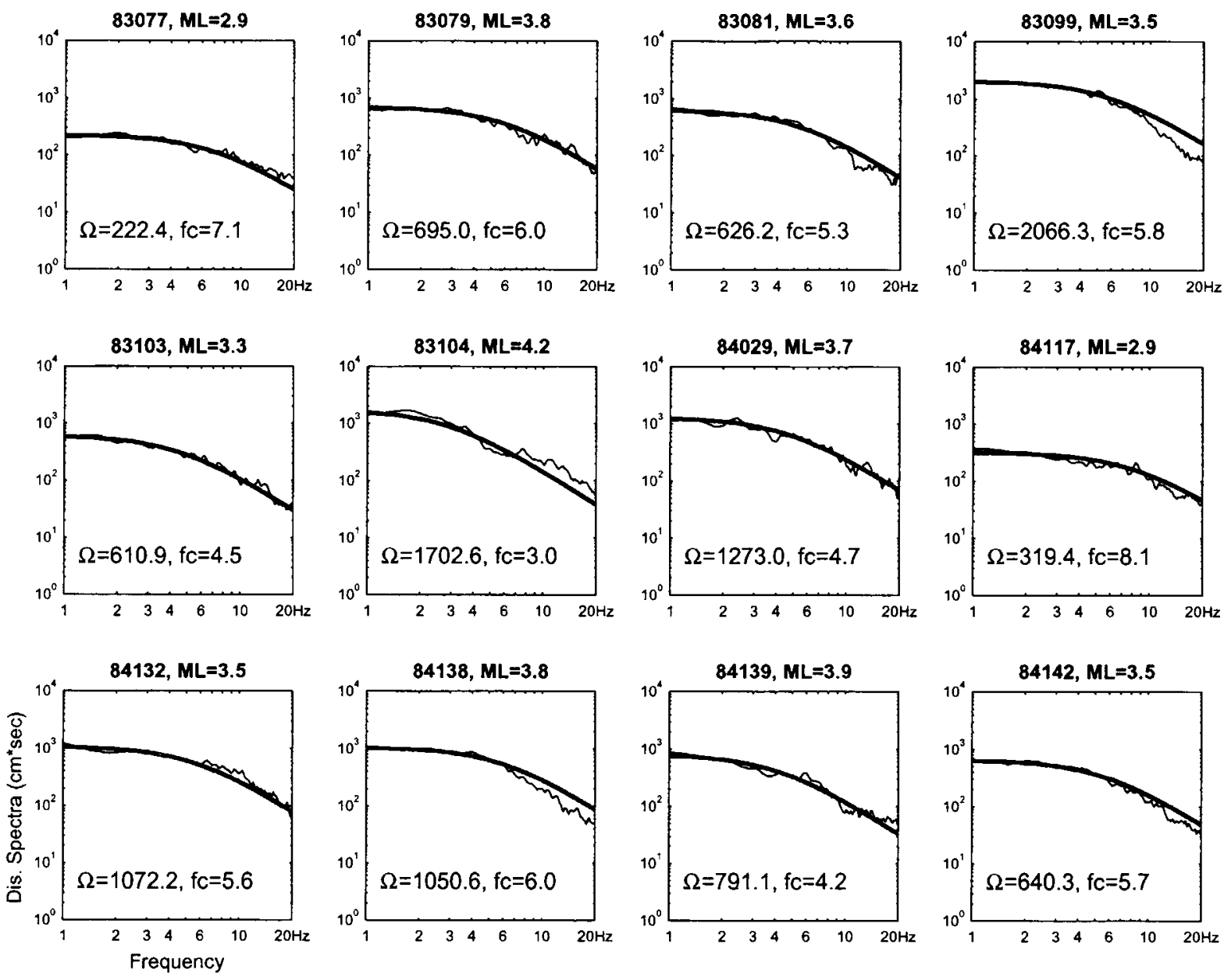

Figure 12. Displacement source spectra for all events. The thin lines represent the average of observations, and the thick lines are the best models found by the referenceindependent technique based on the $\omega$-squared source model. $\Omega$ is the flat level of the displacement source spectrum, and $f_{\mathrm{c}}$ is the corner frequency.

more accurate reference site for seismic hazard analysis and that the reference-independent technique produced accurate absolute site effects for the rock and soil sites investigated in this study. However, when using an underground rock site station or a borehole rock site station as a reference, the effect of surface reflections and the resulting destructive interference must be taken into account. The referenceindependent technique is expected to be useful in other analyses of site effects.

\section{Acknowledgments}

The authors would like to thank Prof. F. J. Sanchez-Sesma of the Instituto de Ingenieria, UNAM, Mexico D.F., and the Instituto Mexicano del Petroleo, Mexico D.F., and Prof. J. G. Anderson of the Seismological Laboratory of the University of Nevada, Reno, Nevada, for helpful comments and suggestions.

This study was supported by the Japan-China Joint Research Program on Strong Ground Motion Prediction and Earthquake Disaster Mitigation and by the Earthquake and Tsunami Disaster Mitigation in the Asia and Pacific Region (EQTAP) Program.

\section{References}

Anderson, J. G., and S. E. Hough (1984). A model for the shape of the Fourier amplitude spectrum of acceleration at high frequencies, Bull. Seim. Soc. Am. 87, 1969-1993.

Andrews, D. J. (1982). Separation of source and propagation spectra of seven Mammoth Lakes aftershocks, Proc. of Workshop XVI, Dynamic Characteristics of Faulting, U.S. Geol. Surv. Open File Rept. 82-591.

Boatwright, J., J. B. Fletcher, and T. E. Fumal (1991). A general inversion scheme for source, site, and propagation characteristics using multiple records sets of moderate-sized earthquakes, Bull. Seism. Soc. Am. 81, 1754-1782.

Bonilla, L. F., J. H. Steidl, G. T. Lindley, A. G. Tumarkin, and R. J. Archuleta (1997). Site amplification in the San Fernando Valley, California: variability of site effect estimation using the $S$-wave, coda, and H/V methods, Bull. Seism. Soc. Am. 87, 710-730.

Boore, D. M., and W. B. Joyner (1997). Site amplification for generic rock sites, Bull. Seism. Soc. Am. 87, 327-341.

Borcherdt, R. D. (1970). Effects of local geology on ground motion near San Francisco Bay, Bull. Seism. Soc. Am. 60, 29-61.

Brune, J. N. (1970). Tectonic stress and the spectra of seismic waves from earthquakes, J. Geophys. Res. 75, 4997-5009.

Brune, J. N. (1971). Correction, J. Geophys. Res. 76, 5002. 
Butler, R., G. S. Stewart, and H. Kanamori (1979). The July 27, 1976 Tangshan, China earthquake: a complex sequence of intraplate events, Bull. Seism. Soc. Am. 69, 207-220.

China-U.S. Joint Project on Strong Ground Motion Measurements (1989). Report on Strong Earthquake Motion Records in China, Vol. 6, Institute of Engineering Mechanics, State Seismological Bureau, Seismological Press, Beijing.

Cranswick, E. (1988). The information content of high-frequency seismograms and the near-surface geologic structure of "hard rock" recording sites, Pageoph 128, 333-363.

Field, E. H., and K. H. Jacob (1995). A comparison and test of various site response estimate techniques, including three that are non-referencesite dependent, Bull. Seism. Soc. Am. 85, 1127-1143.

Hanks, T. C. (1982). $f_{\max }$, Bull. Seim. Soc. Am. 72, 1867-1880.

Hartzell, S. H. (1992). Site response estimation from earthquake data, Bull. Seim. Soc. Am. 82, 2308-2327.

Huang, B. S., and Y. T. Yeh (1997). The fault ruptures of the 1976 Tangshan earthquake sequence inferred from coseismic crustal deformation, Bull. Seism. Soc. Am. 87, 1046-1057.

Iwata, T., and K. Irikura (1986). Separation of source, propagation, and site effects from observed S-waves, Zisin II 39, 579-593 (in Japanese).

Iwata T., and K. Irikura (1989). Source parameters of the 1983 Japan Sea earthquake sequence, J. Phys. Earth 36, 155-184.

Jin, A., C. A. Moya, and M. Ando (2000). Simultaneous determination of site response and source parameters of small earthquakes along the Atotsugawa fault zone, Bull. Seism. Soc. Am. 90, 1430-1445.

Lawson, C. L., and R. J. Hanson (1974). Solving Least Squares Problems, Prentice Hall, New York.

Menke, W. (1989). Geophysical Data Analysis: Discrete Inverse Theory, Academic, New York.

Menke, W., A. L. Lerner-Lam, B. Debendorff, and J. Pacheco (1990). Polarization and coherence of 5 to $30 \mathrm{~Hz}$ seismic wave fields at a hardrock site and their relevance to velocity heterogeneities in the crust, Bull. Seism. Soc. Am. 80, 430-449.

Moya, A., J. Aguirre, and K. Irikura (2000). Inversion of source parameters and site effects from strong ground motion records using genetic algorithms, Bull. Seism. Soc. Am. 90, 977-992.

Nabelek, J., W. P. Chen, and H. Ye (1987). The Tangshan earthquake sequence and its implications for the evolution of the North China basin, J. Geophs. Res. 92, 12,615-12,628.

Phillips, W. S., and K. Aki (1986). Site amplification of coda waves from local earthquakes in central California, Bull. Seism. Soc. Am. 76, 627648.

Schedlock, K. M., J. Baranowski, W. Xiao, and X. L. Hu (1987). The Tangshan aftershock sequence, J. Geophs. Res. 92, 2791-2803.

Schneider, J. F., J. C. Stepp, and N. A. Abrahamson (1992). The spatial variation of earthquake ground motion and effects of local site conditions, Proc. of the Tenth Earthquake Eng. World Conference, 967972.

State Seismological Bureau (1980). Tangshan Earthquake Catalogue, Seismological Press, Beijing, 622 pp. (in Chinese).

Steidl, J. H. (1993). Variation of site response at the UCSB dense array of portable accelerometers, Earthquake Spect. 9, 289-302.

Steidl, J. H., A. G. Tumarkin, and R. J. Archuleta (1996). What is a reference site? Bull. Seism. Soc. Am. 86, 1733-1748.

Vernon, F. L., J. Fletcher, L. Carroll, A. Chave, and E. Sembera (1991). Coherence of seismic body waves from local events as measured by a small-aperture array, J. Geophys. Res. 96, 11,981-11,996.

Xie, X., and Z. Yao (1991). The faulting process of the Tangshan earthquake inverted simultaneously from the teleseismic waveforms and geodesic deformation data, Phys. Earth Planet. Interiors 66, 265-277.

Disaster Prevention Research Institute

Kyoto University

Gokasho, Uji

Kyoto, 611-0011, Japan

matunami@egmdpri01.dpri.kyoto-u.ac.jp

(K.M., K.I.)

Institute of Engineering Mechanics

China Seismological Bureau

9 Xuefu Road

Harbin, China

(W.Z., L.X.) 